\title{
Genetic and Epigenetic Interaction in the Development of Colorectal Cancers
}

\author{
Tomomitsu Tahara ${ }^{1 *}$ and Tomiyasu Arisawa ${ }^{2}$ \\ ${ }^{1}$ Department of Gastroenterology, Fujita Health University School of Medicine, Toyoake, 1-98 Dengakugakubo Kutsukake-cho, Toyoake, Aichi, 470-1192, Japan \\ ${ }^{2}$ Department of Gastroenterology, Kanazawa Medical University, 1-1, Daigaku, Uchinada-machi, Ishikawa, 920-0293, Japan
}

Keywords: DNA methylation; Epigenetics; Genetics; Mutation; Colorectal cancer; Epigenetic therapy

Colorectal cancer (CRC) is one of the most common malignancies, representing the third most common cancer worldwide [1]. Approximately $75 \%$ of all CRCs are sporadic and characterized by genetic lesions, most commonly mutations on TP53, KRAS and APC genes [2,3]. In addition, epigenetic defect in CRCs are also well reported mainly regarding DNA methylation. DNA methylation anomalies define distinct subgroups of $\mathrm{CRC}$, termed $\mathrm{CpG}$ island methylator phenotype (CIMP).The existence of a CIMP and its correlation with clinicopathologic features have been confirmed [4,5]. CIMP-positive CRCs display distinct clinical features, such as greater age, proximal location, and mucinous and poorly-differentiated histopathology. Recent studies have shown that sessile serrated adenomas, mainly observed in the proximal colon are associated with CIMP [6], suggesting the precursor origin of CIMP-positive CRCs is also different from that of CIMP-negative CRCs. Importantly, CIMP-positive CRCs are usually associated with better prognosis [7]; however, patients with CIMP-positive CRCs do not benefit from 5-FU-based adjuvant chemotherapy [8].

It has been thought that epigenetic change is an alternative mechanism in cancer development, however, current knowledge also suggest that most of cancer has mixture of both genetics and epigenetic defects, it would be easy to expect there is also an interaction between genetics and epigenetics in the development of CRCs. Previous researches combining the genetic mutation and CIMP status have identified that there are distinct link between DNA methylation and genetic alterations in CRCs [4]. Consequent study has divided CIMPpositive cases into two different categories (CIMP1 or CIMP-high, and CIMP2 or CIMP-low) suggesting the possibility that CRCs arose from distinct and different genetic and epigenetic abnormalities. CIMP1 cases present intense methylation of multiple genes and are associated with microsatellite instability (MSI) through the epigenetic silencing of a mismatch repair gene (MLH1) as well as BRAF mutation [9]. CIMP2 is characterized by the methylation of a limited group of genes and mutation in KRAS. CIMP-negative cases have less frequent methylation changes and very frequent TP53 mutation and chromosomal instability $[5,9]$. The result is a good example of genetic and epigenetic interaction in the development of cancer and the discovery of CIMP in CRCs is the rand mark for research in the combining of genetic mutation and methylation profiling of carcinomas in order to understand the individual heterogeneity of tumors, which may be useful for a better understanding of the pathogenesis of individual tumors. The concept of genetic and epigenetic interaction in the development of cancers can be well applied for other malignancies such as gastric cancer and glioblastoma. High level CIMP (CIMP-H) gastric cancers with MSI are lacking TP53 or KRAS mutation [10]. Another study in gastric cancer has also revealed an association between the CIMP and oncogenic mutations including CTNNB1, ERBB2, KRAS, and PIK3CA [11]. A comprehensive methylation profiling in glioblastoma suggested the existence of a glioma-CpG island methylator phenotype (G-CIMP), displaying distinct copynumber alterations, and are tightly associated with somatic mutations in IDH1 gene [12].

Recent study in CRCs tried to catalogue both genetics and epigenetics of this cancer type by genome-scale [13]. The result revealed a subset of CRCs which was found to be hypermutated: threequarters of these had the high MSI, hypermethylation and MLH1 silencing, with completely different landscape of mutated genes as shown in non-hypermutated tumors. The result provide a framework for understanding oncogenesis in tumors, highlighting the importance of genomic and epigenomic interactions in human cancers. Although the mechanisms causing methylation phenotypes is remain unclear, revealing the causes of epigenetic instability will help us understand the biology of methylation-positive tumors and may reveal new therapeutic targets.

\section{References}

1. Jemal A, Bray F, Center MM, Ferlay J, Ward E, et al. (2011) Global cancer statistics. CA Cancer J Clin 61: 69-90

2. Rustgi AK (2007) The genetics of hereditary colon cancer. Genes Dev 21 2525-2538.

3. Walther A, Johnstone E, Swanton C, Midgley R, Tomlinson I, et al. (2009) Genetic prognostic and predictive markers in colorectal cancer. Nat Rev Cancer 9: 489-499.

4. Toyota M, Ohe-Toyota M, Ahuja N, Issa JP (2000) Distinct genetic profiles in colorectal tumors with or without the $\mathrm{CpG}$ island methylator phenotype. Proc Natl Acad Sci U S A 97: 710-715.

5. Ahn JB, Chung WB, Maeda O, Shin SJ, Kim HS, et al. (2011) DNA methylation predicts recurrence from resected stage III proximal colon cancer. Cancer 117 1847-1854.

6. Leggett B, Whitehall V (2010) Role of the serrated pathway in colorectal cancer pathogenesis. Gastroenterology 138: 2088-2100.

7. Ogino S, Nosho K, Kirkner GJ, Kawasaki T, Meyerhardt JA, et al. (2009) CpG island methylator phenotype, microsatellite instability, BRAF mutation and clinical outcome in colon cancer. Gut 58: 90-96.

8. Jover R, Nguyen TP, Pérez-Carbonell L, Zapater P, Payá A, et al. (2011) 5 -Fluorouracil adjuvant chemotherapy does not increase survival in patients with CpG island methylator phenotype colorectal cancer. Gastroenterology 140: 1174-1181.

9. Shen L, Toyota M, Kondo Y, Lin E, Zhang L, et al. (2007) Integrated genetic and epigenetic analysis identifies three different subclasses of colon cancer. Proc

*Corresponding author: Tomomitsu Tahara, Department of Gastroenterology Fujita Health University School of Medicine, Toyoake, 1-98 Dengakugakubo Kutsukake-cho, Toyoake, Aichi, 470-1192, Japan, Tel: +81-562-939240; Fax: +81 56293 8300; E-mail: tomomiccyu@yahoo.co.jp

Received May 20, 2013; Accepted June 06, 2013; Published June 08, 2013 Citation: Tahara T, Arisawa T (2013) Genetic and Epigenetic Interaction in the Development of Colorectal Cancers. Human Genet Embryol 3: 109 doi:10.4172/2161-0436.1000109

Copyright: ( $) 2013$ Tahara T, et al. This is an open-access article distributed unde the terms of the Creative Commons Attribution License, which permits unrestricted use, distribution, and reproduction in any medium, provided the original author and source are credited. 
Citation: Tahara T, Arisawa T (2013) Genetic and Epigenetic Interaction in the Development of Colorectal Cancers. Human Genet Embryol 3: 109. doi:10.4172/2161-0436.1000109

Page 2 of 2

Natl Acad Sci U S A 104: 18654-18659.

10. Kusano M, Toyota M, Suzuki H, Akino K, Aoki F, et al. (2006) Genetic, epigenetic, and clinicopathologic features of gastric carcinomas with the $\mathrm{CpG}$ island methylator phenotype and an association with Epstein-Barr virus. Cancer 106: 1467-1479.

11. Kim JG, Takeshima H, Niwa T, Rehnberg E, Shigematsu Y, et al. (2013) Comprehensive DNA methylation and extensive mutation analyses reveal an association between the CpG island methylator phenotype and oncogenic mutations in gastric cancers. Cancer Lett 330: 33-40.

12. Noushmehr H, Weisenberger DJ, Diefes K, Phillips HS, Pujara K, et al. (2010) Identification of a CpG island methylator phenotype that defines a distinct subgroup of glioma. Cancer Cell 17: 510-522.

13. Cancer Genome Atlas Network (2012) Comprehensive molecular characterization of human colon and rectal cancer. Nature 487: 330-337. 